\title{
Randomized controlled trial comparing nasal intermittent positive pressure ventilation and nasal continuous positive airway pressure in premature infants after tracheal extubation
}

\author{
Daniela Franco Rizzo Komatsu¹, Edna Maria de Albuquerque Diniz ${ }^{2 *}$, Alexandre Archanjo Ferraro³, \\ Maria Esther Jurvest Rivero Ceccon ${ }^{4}$, Flávio Adolfo Costa Vaz ${ }^{5}$ \\ ${ }^{1}$ MSc in Pediatrics from Faculdade de Medicina, Universidade de São Paulo (FMUSP), São Paulo, SP, Brazil \\ ${ }^{2}$ Associate Professor, Habilitation (BR: Livre-docência) in Neonatology, Department of Pediatrics, FMUSP, São Paulo, SP, Brazi \\ ${ }^{3}$ PhD Professor, Division of Preventive and Social Pediatrics, Department of Pediatrics, FMUSP, São Paulo, SP, Brazil \\ 4Professor, Habilitation (BR: Livre-docência) in Neonatology, Department of Pediatrics, FMUSP, São Paulo, SP, Brazi \\ ${ }^{5}$ Full Professor, Department of Pediatrics, FMUSP, São Paulo, SP, Brazil
}

Study conducted at the Department of Pediatrics, Faculdade de Medicina, Universidade São Paulo (FMUSP), São Paulo, SP, Brazil

Article received: 6/29/2016 Accepted for publication: $7 / 26 / 2016$

*Correspondence: Departamento de Pediatria Address: Av. Dr. Enéas de Carvalho Aguiar, 647

São Paulo, SP - Brazil Postal code: 05403-900 edna.diniz@hc.fm.usp.br

http://dx.doi.org/10.1590/1806-9282.62.06.568

\section{SUMMARY}

Objective: To analyze the frequency of extubation failure in premature infants using conventional mechanical ventilation (MV) after extubation in groups subjected to nasal intermittent positive pressure ventilation (nIPPV) and continuous positive airway pressure (nCPAP).

Method: Seventy-two premature infants with respiratory failure were studied, with a gestational age $(\mathrm{GA}) \leq 36$ weeks and birth weight $(\mathrm{BW})>750 \mathrm{~g}$, who required tracheal intubation and mechanical ventilation. The study was controlled and randomized in order to ensure that the members of the groups used in the research were chosen at random. Randomization was performed at the time of extubation using sealed envelopes. Extubation failure was defined as the need for re-intubation and mechanical ventilation during the first 72 hours after extubation.

Results: Among the 36 premature infants randomized to nIPPV, six (16.6\%) presented extubation failure in comparison to 11 (30.5\%) of the 36 premature infants randomized to nCPAP. There was no statistical difference between the two study groups regarding BW, GA, classification of the premature infant, and MV time. The main cause of extubation failure was the occurrence of apnea. Gastrointestinal and neurological complications did not occur in the premature infants participating in the study. Conclusion: We found that, despite the extubation failure of the group of premature infants submitted to nIPPV being numerically smaller than in premature infants submitted to nCPAP, there was no statistically significant difference between the two modes of ventilatory support after extubation.

Keywords: infant respiratory distress syndrome, continuous positive airway pressure, intermittent positive pressure ventilation, premature, controlled and random clinical trials.

\section{INTRODUCTION}

Given the advances in neonatology, particularly in ventilatory assistance, premature infants have increasingly survived, especially those with very low birth weight (VLBW) ${ }^{1,2}$ Respiratory distress is one of the most common diseases that affect these premature infants, and they most often require respiratory support through the use of mechanical ventilation (MV). ${ }^{3,4}$

Medical conduct from the respiratory perspective has been directed to minimize the need for prolonged MV through respiratory assistance where aggression and time are kept as low as possible in order to reduce barotrauma and oxygen toxicity. ${ }^{5,6}$ High morbidity occurs even with the use of surfactant, especially in premature infants requiring MV for a prolonged period. ${ }^{4}$ Thus, attempts at extubation should be performed as early as possible. However, extubation failure constitutes a frequent problem in these patients, mainly because premature infants easily develop hypoventilation and atelectasis, causing episodes of severe apnea. ${ }^{1,4,7}$ Extubation failure is concern- 
ing because in addition to prolonging the ventilatory support time, it also increases the likelihood of airway trauma and nosocomial infection upon re-intubation.

Some meta-analysis studies have shown the use of various interventions to reduce atelectasis or respiratory failure after extubation of premature infants. These interventions include the use of nasal continuous positive airway pressure (nCPAP) ${ }^{8,9}$ which has also demonstrated extubation failure at around $28 \%$ in newborns, which justifies the development and/or improvement of methods to increase its efficacy. ${ }^{9}$

A new non-invasive, nasal method known as nasal intermittent positive pressure ventilation (nIPPV) has been used in extubated premature infants in order to decrease the incidence of extubation failure. This ventilation method seems to ensure better respiratory support, particularly in premature infants with VLBW, decreasing the need for tracheal re-intubation. ${ }^{1,10,11}$ Although there are few studies on the use of nIPPV, most research consists of a small number of newborns and/or observation for a short period after extubation. ${ }^{1,7,12}$

\section{Method}

\section{Sample}

Seventy-two newborns were studied, all with a GA $\leq 36$ weeks and 6 days and $\mathrm{BW}>750 \mathrm{~g}$, and respiratory failure requiring orotracheal intubation and mechanical ventilation at the Unidade de Cuidados Intensivos Neonatal, Instituto da Criança, Hospital das Clínicas, Faculdade de Medicina, Universidade de São Paulo (HC-FMUSP) and the Unidade de Terapia Intensiva Neonatal, Hospital Estadual Mário Covas de Santo André (UTIN HESA).

The study excluded premature infants with congenital anomalies that could compromise the cardiorespiratory system.

The Research Project was approved by the Ethics Committee of both services (HC-FMUSP and UTIN HESA).

Informed consent was obtained from the guardians of all of the premature infants studied.

\section{Definitions}

- Respiratory failure: Respiratory distress characterized by the presence of acute clinical symptoms (intercostal and/or subcostal retraction, nasal flaring, grunting and cyanosis) and laboratory findings [the need to maintain the fraction of inspired oxygen $\left(\mathrm{FiO}_{2}\right)$ over $65 \%$ to maintain the saturation of $\mathrm{O}_{2}$ between 90 and $92 \%$, the partial pressure of $\mathrm{CO}_{2}\left(\mathrm{PaCO}_{2}\right)>65$ $\mathrm{mmHg}$ and $\mathrm{pH}<7.25$ ] with the need for tracheal intubation and mechanical ventilation.
- Extubation failure: The occurrence of clinical and laboratory signs of acute respiratory failure during the 72 hours under study, which could evolve into respiratory fatigue and recurrent severe apnea, with the need for tracheal intubation and mechanical ventilation.

- Neurological complications: The presence of peri-intraventricular or intraventricular hemorrhage (IVH) according to Papile's classification. ${ }^{13}$

- Gastrointestinal complications: The occurrence of food intolerance characterized by the presence of gastric residue and/or abdominal distension.

- Sepsis: Diagnosed by the presence of a positive blood culture and/or clinical and laboratory signs, resulting in a clinical decision of treatment with antibiotics for at least 10 days.

- Bronchopulmonary dysplasia (BPD): Defined as oxygen dependence with a corrected GA of 36 weeks and/or presence of characteristic radiographic parenchymal abnormalities. ${ }^{8}$

- Patent ductus arteriosus (PDA): Characterized through clinical examination and echocardiogram.

\section{Study design}

Premature infants who fulfilled the inclusion criteria of the study received treatment for respiratory failure according to the routine of the services, including the use of an exogenous surfactant.

Premature infants with a GA < 34 weeks and/or BW $<1500$ g received treatment with aminophylline.

In order to obtain two homogeneous samples for the study, the distribution of premature infants was performed by randomization, which was carried out at the time of extubation using sealed envelopes: 36 cards were identified as nIPPV and 36 as nCPAP, placed in dark envelopes and distributed randomly in order to conduct the draw, and subsequently discarded.

When the premature infant reached the criteria for extubation from mechanical ventilation, that is, the ventilatory parameters: $\operatorname{PIP}$ (peak inspiratory pressure) $\leq 16 \mathrm{cmH}_{2} 0$; PEEP (positive end-expiratory pressure) $\leq 4 \mathrm{cmH}_{2} 0 ; \mathrm{RF}$ (respiratory frequency) $=12 \mathrm{bpm} ; \mathrm{FiO}_{2} \leq 40 \%, \mathrm{MAP}$ (mean airway pressure) $\leq 7 \mathrm{cmH}_{2} \mathrm{O}$; and laboratory parameters: $\mathrm{pH} \geq 7.25 ; \mathrm{PaO}_{2} \geq 50 \mathrm{mmHg} ; \mathrm{PaCO}_{2} \leq 60 \mathrm{mmHg}$; hematocrit $\geq 40 \%$, extubation was performed followed by installation of nIPPV or nCPAP, according to the randomization result. Newport ${ }^{\circledR}$ - model E100 or Inter III $^{\circledR}$ fans were used, as well as nasal tubes by Argyle ${ }^{\circledR}$ or Hudson RCI ${ }^{\circledR}$ marks.

The initial parameters used for the premature infants randomized to nIPPV were: $\mathrm{RF}=12 \mathrm{bpm} ; \mathrm{PIP}=16 \mathrm{cmH}_{2} \mathrm{O}$; $\mathrm{PEEP}=6 \mathrm{cmH}_{2} 0 ; \mathrm{FiO}_{2} \leq 40 \%$. 
The initial parameters used for the premature infants randomized to nCPAP were: $\mathrm{P}$ (pressure) $=6 \mathrm{cmH}_{2} 0$; $\mathrm{FiO}_{2} \leq 40 \%$.

The blood gases were monitored during the first 24 hours after extubation and/or when necessary.

During the study, the premature infants were fed via enteral route through orogastric tubes every 3 hours or by continuous infusion, if necessary. Gastric residue was measured before the next feeding.

The study was concluded after an extubation time of 72 hours or when the premature infant fulfilled the criteria for extubation failure.

\section{Statistical analysis}

The study groups were compared using Student's t-test and chi-square test. The cutoff point for rejecting the null hypothesis was $\mathrm{p} \leq 0.05$.

The univariate analysis was conducted using the Mantel-Haenszel test. A multivariate logistic analysis was conducted.

The association and univariate analyses were undertaken using EPI Info ${ }^{\mathrm{TM}}$ software version $6.0 \mathrm{~b}$. The multivariate logistic regression was carried out using Stata software version 8.0.

\section{Results}

Thirty-six of the 72 premature infants studied were randomized to receive nIPPV, and 36 to receive nCPAP. The average birth weight was between 1,271 and $1,425 \mathrm{~g}$ $(\mathrm{p}=0.10)$, respectively; and the average $\mathrm{GA}$ was between 30.2 and 31.3 weeks $(\mathrm{p}=0.043)$, respectively. As shown in Table 1, the distribution of the demographic and birth variables were similar, with the exception of gestational age, which had a significant difference between the two study groups $(\mathrm{p}=0.04)$.

To avoid the interference of potential confounding variables we compared the rates of common complications of prematurity prior to extubation.

The incidence of PDA in the nIPPV group was greater than the percentage in the nCPAP group $(19.4 \% v$ s. $5.5 \%)$, without any statistical difference $(\mathrm{p}=0.15)$. Likewise, the two study groups were similar regarding the incidence of sepsis, BPD and IVH, with no statistically significant difference. We emphasize that among the two study groups there was no premature infant with a diagnosis of necrotizing enterocolitis.

Ventilatory and clinical evolution prior to extubation was similar in both groups (Table 2). Aminophylline was used in $91.6 \%$ of the children who were randomized to

TABLE 1 Demographic and initial clinical data of 72 premature infants with respiratory failure undergoing $n C P A P$ or nIPPV ventilation.

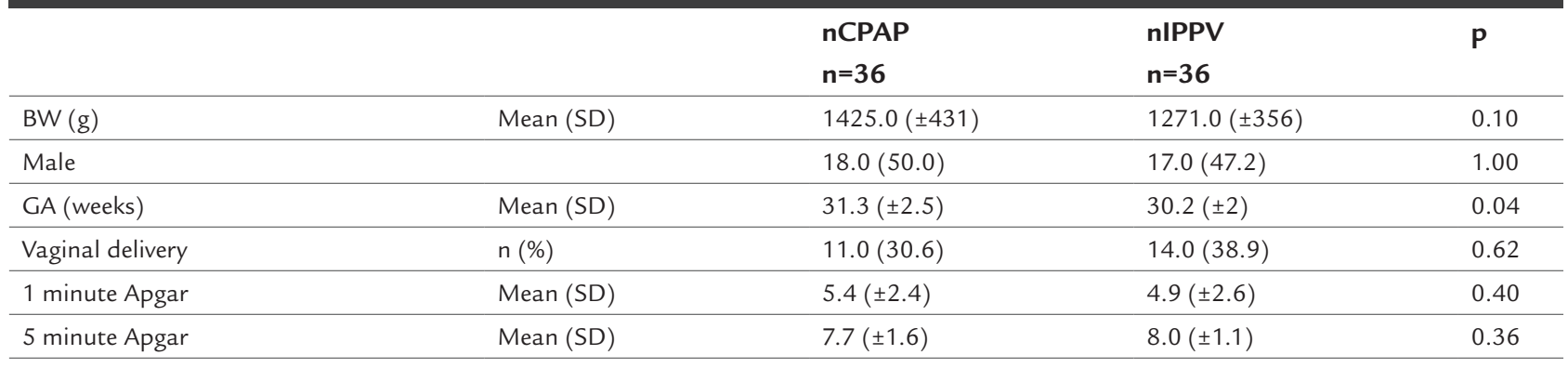

SD: standard deviation; BW: birth weight; GA: gestational age.

TABLE 2 Respiratory support time and incidence of complications after extubation in 72 infants undergoing nCPAP or nIPPV ventilation.

\begin{tabular}{|c|c|c|c|c|}
\hline & & $\begin{array}{l}n C P A P \\
n=36\end{array}$ & $\begin{array}{l}\text { nIPPV } \\
n=36\end{array}$ & $\mathbf{p}$ \\
\hline Time of use of NIV (days) & Mean (SD) & $2.0( \pm 2.7)$ & $1.5( \pm 0.7)$ & 0.28 \\
\hline $\mathrm{O}_{2}$ time after NIV (days) & Mean (SD) & $3.7( \pm 3.7)$ & $3.0( \pm 2.2)$ & 0.33 \\
\hline $\mathrm{pH}^{*}$ & Mean (SD) & $7.38( \pm 0.07)$ & $7.34( \pm 0.1)$ & 0.05 \\
\hline $\mathrm{PaCO}_{2}{ }^{*}$ & Mean (SD) & $36.3( \pm 10.7)$ & $34.8( \pm 13.0)$ & 0.59 \\
\hline Gastric residue & $\mathrm{n}(\%)$ & $11(30.5)$ & $12(33.3)$ & 0.80 \\
\hline Abdominal distension & $\mathrm{n}(\%)$ & $2(5.5)$ & $2(5.5)$ & 1.00 \\
\hline Apnea & $\mathrm{n}(\%)$ & $6(16.6)$ & $3(8.3)$ & 0.48 \\
\hline
\end{tabular}

NIV: non-invasive ventilation; * on the first day after extubation. 
nCPAP, and in $86.1 \%$ of those randomized to the nIPPV group, with no statistical difference. Most of the premature infants received at least one dose of exogenous surfactant $(80.5 \%$ in the nIPPV group and $83.3 \%$ in the $\mathrm{nC}$ PAP group, $\mathrm{p}=1.00)$. The average time on mechanical ventilation (6.2 and 7.3 days respectively, $\mathrm{p}=0.59$ ) and the average $\mathrm{FiO}_{2}$ prior to extubation (29.9 and 28.8 respectively, $\mathrm{p}=0.71$ ) were similar between the two groups.

The average time of use of the ventilatory methods was two days for nCPAP and one day and a half for the nIPPV group $(p=0.28)$. Also regarding use of the respiratory assistance methods, inhaled oxygen support time after the suspension of the ventilatory methods was also similar. As for blood gas analysis, $\mathrm{pH}$ values in the nIPPV group were lower than in the nCPAP group (7.34 vs. 7.38). Although this difference was statistically significant $(\mathrm{p}=0.05)$, there was no clinical significance because both results are in the normal range, and therefore could not interfere in the occurrence of extubation failure. The values of $\mathrm{PaCO}_{2}$ on the first day after extubation were also similar in both groups.

In our study the occurrence of gastric residue or abdominal distension that would prohibit feeding was similar between the two groups, and none of the patients presented a diagnosis of gastric perforation.

The evaluation of extubation failure among the premature infants who were randomized to the nIPPV group and the nCPAP group showed no statistically significant difference. Among the 36 premature infants randomized to receive nIPPV, six $(16.6 \%)$ presented extubation failure in comparison to 11 (30.5\%) of the 36 premature infants randomized to nCPAP (Chart 1).

We sought to verify if there was a relationship between extubation failure of the two methods and BW, GA, classification of the premature infant, and the MV time. We found no statistically significant difference between the association of the characteristics described above and the methods under study, and all adjusted relative risk estimates (nIPPV versus $\mathrm{nCPAP}$ ) were not greatly different from the gross value of 0.55 .

In relation to the factors determining failures, that is, recurrent episodes of apnea ( $54.5 \%$ s. $16.6 \%)$, frequent decreases in oxygen saturation $(27.2 \%$ vs. $50 \%)$ and clinical signs of respiratory distress ( $18.1 \%$ vs. $33.3 \%)$, we did not find a statistically significant difference between the nCPAP and nIPPV groups. Although the occurrence of apnea in the nCPAP group was numerically higher in relation to the nIPPV group ( $6 v$ s. 1$)$, this difference was not significant $(\mathrm{p}=0.30)$.

Most premature infants participating in the study underwent a cranial ultrasound after extubation, and the results showed no statistically significant difference between the two study groups.

The occurrence of side effects was not observed during the 72 hour period of the study.

\section{Discussion}

In recent decades the number of premature infants with a VLBW requiring prolonged mechanical ventilation has increased, and currently the challenge for neonatologists

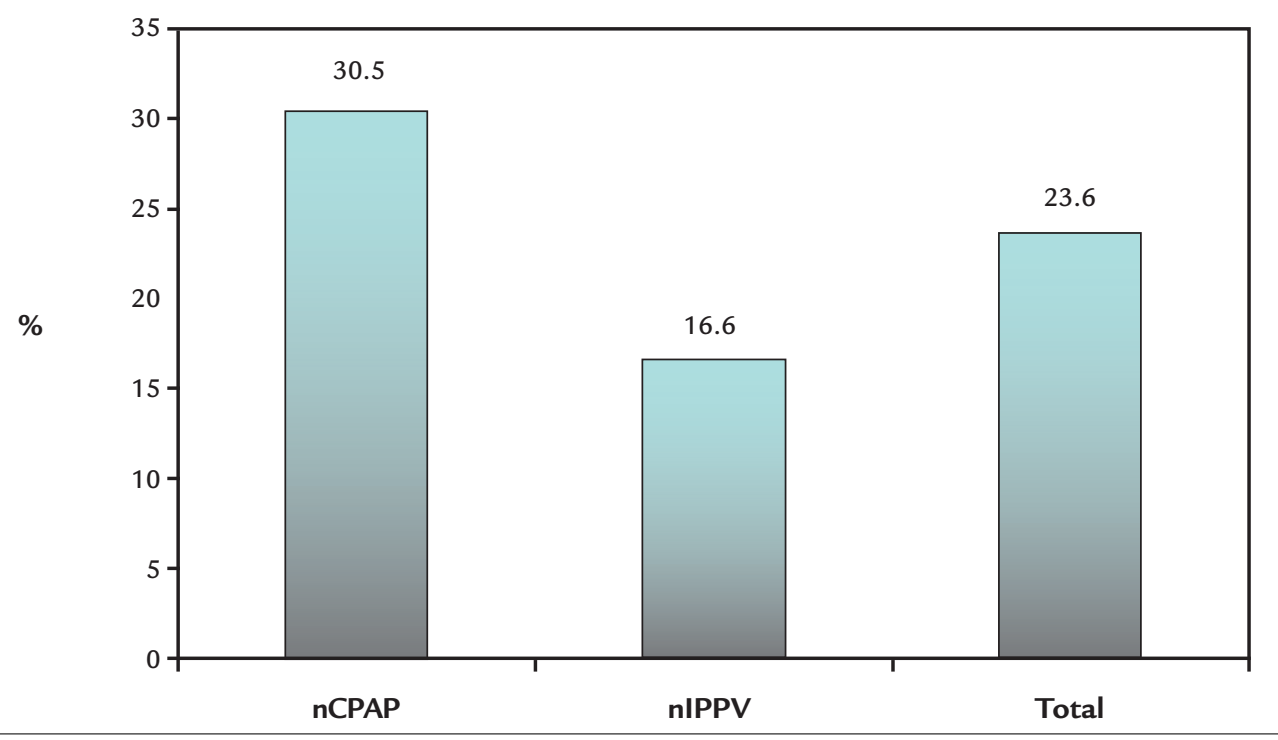

CHART 1 Extubation failure among the 72 premature infants with respiratory failure submitted to ventilation by $\mathrm{nCPAP}$ or $\mathrm{nIPPV}$. nCPAP: nasal continuous positive airway pressure; nIPPV: nasal intermittent positive pressure ventilation. 
is no longer treating newborns with low birth weight but those with extremely low birth weight $(\mathrm{PN}<1,000 \mathrm{~g}) \cdot{ }^{14}$ Efforts to limit the duration of MV have been conducted with the purpose of reducing not only the incidence of mortality but also morbidity, which is high in this population of premature infants. However, early extubation has been accompanied by various difficulties, particularly due to instability of the ribcage, the presence of alveolar atelectasis and residual pulmonary damage. ${ }^{9}$ Despite the non-invasive ventilation method used, the extubation failure rate was $23.6 \%$, a similar result to those found in the literature. Barrington et al., in their controlled and randomized study, compared the extubation failure rate of 54 premature infants with $\mathrm{BW}<1,250 \mathrm{~g}$ and GA of 26.1 weeks, verifying a failure rate of $29.6 \% .{ }^{1}$ Among the 64 premature infants studied by Khalaf et al., around $21.8 \%$ showed extubation failure during the use of non-invasive ventilation. ${ }^{6}$ When assessing extubation in premature infants with a BW $<1,000 \mathrm{~g}$, Stefanescu et al. reported failure in $38.2 \%$ of their patients. ${ }^{15}$

In our study, even though the distribution of the failure frequencies showed a numerically lower failure rate in premature infants treated with nIPPV compared to those undergoing nCPAP, there was no statistically significant difference between the two methods of ventilatory support after extubation.

The consensus in the literature is that the nIPPV method can cause gastrointestinal complications due to the possibility of gastric distension leading to suspension of feeding, higher frequency of gastric residue, and even gastric perforation. Garland et al. conducted a retrospective evaluation of 20 premature infants that presented gastric perforation in order to determine whether the type of ventilatory support used was associated with the occurrence of gastric perforation. ${ }^{16}$ The authors found that ventilation through the use of a facial mask or nasal prong favored an increased risk of gastric perforation at around $30 \%$ compared to the use of a tracheal tube. Nevertheless, the authors themselves call attention to possible bias in the study, which is the underdiagnosis of necrotizing enterocolitis. They also point out that most premature infants participating in the study received both types of ventilation (via the nasal prong and endotracheal tube), therefore gastric perforation could have occurred during the ventilation period with the tracheal tube, and the symptoms may have manifested during the use of the nasal prong or the facial mask. ${ }^{16}$

In our study the occurrence of gastric residue or abdominal distension that could prohibit feeding was similar between the two study groups, and none of the pa- tients participating in the research presented gastric perforation. Kugelman et al. also did not observe the occurrence of gastrointestinal complications in their study. ${ }^{17}$ Similar facts have been described by other authors. ${ }^{9,18,19}$ Barrington et al. did not demonstrate an increased incidence of abdominal distention or food intolerance in the 54 premature infants subject to two non-invasive ventilation methods, and also did not find any cases of gastric perforation. ${ }^{1}$ A similar fact was described by Kiciman et al. among the 14 premature infants studied. ${ }^{10}$

In some studies we verified variable rates in relation to extubation failure, sometimes associated with lower birth weight and gestational age. ${ }^{1,15,20,21}$ As such, we sought to verify if there was a relationship between extubation failure in the two methods and the BW and GA, classification of the premature infant, and the MV time. We found that there was no significant difference between the association of the characteristics described and the methods under study.

The mechanism explaining the fact that nIPPV is more beneficial or effective than nCPAP has not yet been fully elucidated. Kishore et al. believe that with nIPPV there is better alveolar recruitment, with improved residual functional capacity. ${ }^{11}$ Moretti et al. consider that nIPPV may increase upper airway patency by creating high pressure in the pharynx and promoting intermittent inflation of the pharynx, thereby activating the respiratory rhythm. ${ }^{22}$ In their study, the authors performed pulmonary function tests and found that during nIPPV the pulmonary volumes (tidal volume and minute volume) were significantly higher compared to nCPAP, and the values of the transcutaneous $\mathrm{PaCO}_{2}$ were also significantly lower compared to those in the nCPAP group. ${ }^{22}$ Lin et al. also believe that the intermittent pressure created in the pharynx is higher when using nIPPV, and that the flow of air passing through the pharynx can activate the pharyngeal dilator muscles, stimulating breathing and reducing episodes of apnea. According to the authors, increases in chest wall incursions and respiratory impulses were observed when the premature infant underwent nIPPV. These impulses were not noted when the premature infant received nCPAP. ${ }^{7}$ There is evidence that these impulses are induced by nIPPV, and could be responsible for recruiting more alveoli and reversing areas of pulmonary microatelectasis, which explains its success. ${ }^{17}$

The main factor related to extubation failure, regardless of the study group, was sleep apnea, present in $41.2 \%$ of the premature infants. In the studies by Barrington et al., the occurrence of apnea constituted one of the main causes of extubation failure. ${ }^{1}$ In the research 
by Stefanescu et al., the occurrence of apnea and bradycardia was responsible for failure in $58 \%$ of the premature infants participating in the study. ${ }^{15}$ Likewise, Khalaf et al. reported episodes of apnea as being responsible for $41 \%$ of failures. ${ }^{6}$ When evaluating the incidence of apnea in relation to the study group, the authors observed that, in the nCPAP group, the occurrence of apnea was responsible for $46.7 \%$ of failures, and $32.3 \%$ in the nIPPV group, with no significant difference, similar to our findings. With respect to the number of episodes of apnea, the premature infants submitted to nIPPV showed a lower number in relation to the group submitted to nCPAP, although this difference was not significant. Among the three studies evaluated by Davis et al. in their meta-analysis, only one investigated the occurrence of apnea, and the results of which showed a tendency to reduce the episodes of apnea in premature infants randomized to nIPPV, although not statistically significant. ${ }^{9}$

During the study period, whether in the nIPPV or nCPAP method, the occurrence of side effects was not observed, similar to that noted by other authors. ${ }^{1,6,7,11,19}$

Barrington et al. and Davis et al. were unanimous in affirming that nIPPV is a useful and effective method to increase the benefits of nCPAP in the prevention of extubation failure of premature infants in the first hours after extubation. ${ }^{1,8}$

Likewise, Khalaf et al. consider nIPPV as more effective than nCPAP in the weaning of premature infants with respiratory distress syndrome (RDS) using mechanical ventilation, and recommend that nIPPV should be used as the primary extubation method even in premature infants with impaired pulmonary function. ${ }^{6}$

Kahramaner et al. also concluded that nIPPV has a better effect than nCPAP after extubation of premature infants, as it reduced the occurrence of atelectasis, the need for re-intubation and even the number of deaths. ${ }^{21}$

\section{Conclusion}

Although the distribution of the failure frequencies showed a numerically lower failure rate in premature infants treated with nIPPV compared to those undergoing nCPAP, there was no statistically significant difference between the two methods of ventilatory support after extubation.

We believe that, to the extent in which mechanical ventilation can be avoided, through the use of non-invasive ventilation, particularly in the nIPPV method, there will be a decrease in the incidence of sequelae such as bronchopulmonary dysplasia and cerebral hemorrhage, improving not only survival, but also the quality of life of these patients.

\section{Resumo}

Estudo controlado e randomizado entre uso de ventilação positiva intermitente e pressão positiva contínua em vias aéreas em recém-nascidos prematuros após a extubação traqueal

Objetivo: analisar a frequência de falha da extubação em recém-nascidos pré-termo (RNPT) em uso de ventilação mecânica (VM) convencional após a extubação traqueal nos grupos submetidos à ventilação por pressão positiva intermitente por via nasal (nIPPV) e pressão positiva contínua em vias aéreas (nCPAP).

Método: foram estudados 72 RNPT portadores de insuficiência respiratória, com idade gestacional $(\mathrm{IG}) \leq 36$ semanas e peso de nascimento $(\mathrm{PN})>750 \mathrm{~g}$, que necessitaram de entubação traqueal e ventilação mecânica. $\mathrm{O}$ estudo foi controlado e randomizado a fim de garantir a aleatoriedade na escolha dos integrantes dos grupos. A randomização foi realizada no momento da extubação por meio de envelopes selados. Falha da extubação foi definida como necessidade de reentubação e ventilação mecânica durante as primeiras 72 horas após a extubação.

Resultados: entre os $36 \mathrm{RN}$ randomizados para nIPPV, seis $(16,6 \%)$ apresentaram falha de extubação em comparação a 11 (30,5\%) dos $36 \mathrm{RN}$ randomizados para nCPAP. Não houve diferença estatística entre os dois grupos de estudo em relação a PN, IG, classificação do RN e tempo de VM. A principal causa de falha da extubação foi a ocorrência de apneia. Complicações gastrointestinais e neurológicas não ocorreram nos RNPT participantes do estudo.

Conclusão: constatamos que no grupo dos RNPT submetidos à nIPPV, apesar da falha da extubação ser numericamente menor que nos RNPT submetidos à nCPAP, não houve diferença estatisticamente significante entre os dois modos de suporte ventilatório após a extubação.

Palavras-chave: síndrome do desconforto respiratório do recém-nascido, pressão positiva contínua nas vias aéreas, ventilação com pressão positiva intermitente, prematuro, ensaios clínicos controlados e aleatórios.

\section{References}

1. Barrington KJ, Bull D, Finer NN. Randomized trial of nasal synchronized intermittent mandatory ventilation compared with continuous positive airway pressure after extubation of very low birth weight infants. Pediatrics. 2001; 107(4):638-41.

2. Tomminska V, Heinonen K, Lehtonen L, Renlund M, Saarela T, Tamela O, et al No improvement in outcome of nationwide extremely low birthweight infant populations between 1996-1997 and 1999-2000. Pediatrics. 2007; 119(1):29-36. 
3. Malik RK, Gupta RK. A two year experience in continuous positive pressure ventilation using nasal prongs and pulse oximetry. Med J Armed Forces India. 2003; 59(1):36-9.

4. Ramanathan R, Sekar KC, Rasmussen M, Bhatia J, Soll RF. Nasal intermittent positive pressure ventilation after surfactant treatment for respiratory distress syndrome in preterm infants < 30 weeks' gestation: a randomized, controlled trial. J Perinatol. 2012; 32(5):336-43.

5. Jobe AH, Bancalari E. Bronchopulmonary dysplasia. Am J Respir Crit Care Med. 2001; 163(7):1723-9.

6. Khalaf MN, Brodsky N, Hurley J, Bhandari V. A prospective randomized, controlled trial comparing synchronized nasal intermittent positive pressure ventilation versus nasal continuous positive airway pressure as modes of extubation. Pediatrics. 2001; 108(1):13-7.

7. Lin CH, Tsay WH, Lin YJ, Wang ST, Yeh TF. Efficacy of nasal intermittent positive pressure ventilation in treating apnea of prematurity. Pediatr Pulmonol. 1998; 26(5):349-53.

8. Davis PG, Lemyre B, De Paoli AG. Nasal intermittent positive pressure ventilation (NIPPV) versus nasal continuous positive airway pressure (NCPAP) for preterm neonates after extubation. Cochrane Database Syst Rev. 2001(3):CD003212.

9. Davis PG, Hendderson-Smart DJ. Nasal continuous positive airways pressure immediately after extubation for preventing morbidity in preterm infants. Cochrane Database Syst Rev. 2003;(2):CD000143.

10. Kiciman NM, Andreasson B, Bernstein G, Mannino FL, Rich W, Henderson $\mathrm{C}$, et al. Thoracoabdominal motion in newborns during ventilation delivered by endotracheal tube or nasal prongs. Pediatr Pulmonol. 1998; 25(3):175-81.

11. Sai Sunil Kishore M, Dutta S, Kumar P. Early nasal intermittent positive pressure ventilation versus continuous positive airway pressure for respiratory distress syndrome. Acta Paediatr 2009; 98(8):1412-5.

12. Ryan CA, Finer NN, Peters KL. Nasal intermittent positive-pressure ventilation offers no advantages over nasal continuous positive airway pressure in apnea of prematurity. Am J Dis Child. 1989; 143(10):1196-8.

13. Papile LA, Burstein J, Burstein R, Koffler H. Incidence and evolution of subependymal and intraventricular hemorrhage: a study of infants with weight less than 1500 grams. J Pediatr. 1978; 92(4):529-34.
14. Darlow BA, Cust AE, Donoghue DA. Improved outcomes for very low birthweight infants: evidence from New Zealand national population based data. Arch Dis Child Fetal Neonatal. 2003; 88:F23-8.

15. Stefanescu BM, Murphy WP, Hansell BJ, Fuloria M, Morgan TM, Aschner $\mathrm{JL}$. A randomised, controlled trial comparing two different continuous positive airway pressure systems for successful extubation of extremely low birth weight infants. Pediatrics. 2003; 112(5):1031-8.

16. Garland JS, Nelson DB, Rice T, Neu J. Increased risk of gastrointestinal perforation in neonates mechanically ventilated with either face mask or nasal prongs. Pediatrics. 1985; 76(3):406-10.

17. Kugelman A, Feferkorn I, Riskin A, Chistyakov I, Kaufman B, Bader D. Nasal intermittent mandatory ventilation versus nasal continuous positive airway pressure for respiratory distress syndrome: a randomized, controlled, prospective study. J Pediatr. 2007; 150(5):521-6.

18. De Paoli AG, Davis PG, Lemyre B. Nasal continuous pressure versus nasal intermittent positive pressure ventilation for preterm neonates: a systematic review and meta-analysis. Acta Paediatr. 2003; 92(1):70-5.

19. Khorana M, Paradeevisut H, Sangtawesin V, Kanjanapatanakul W, Chotigeat $\mathrm{U}$, Ayutthaya JK. A randomized trial of non-synchronized nasopharyngeal intermittent mandatory ventilation (nsNIMV) vs. nasal continuous positive airway pressure (NCPAP) in the prevention of extubation failure in pre-term $<$ 1,500 grams. J Med Assoc Thai. 2008; 91 Suppl 3:136-42.

20. Dimitrou G, Greenough A, Endo A, Cherian S, Rafferty GF. Prediction of extubation failure in preterm infants. Arch dis Child Fetal Neonatal Ed. 2002; 86(1):F32-5.

21. Kahramaner Z, Erdemir A, Turkoglu E, Cosar H, Suctuoglu S, Ozer EA. Unsyncronized nasal intermitente positive pressure versus nasal continuous positive airway pressure in preterm infants after extubation. J Matern Fetal Neonatal Med. 2014; 27(9):926-9.

22. Moretti C, Gizzi C, Papoff P, Lampariello S, Capoferri M, Calcagnini G, et al. Comparing the effects of nasal synchronized intermittent positive pressure ventilation (nSIPPV) and nasal continuous positive airway pressure (nCPAP) after extubation in very low birth weight infants. Early Hum Dev. 1999; 56(2-3):167-77. 